\title{
O Caminho de Santiago em Gaia. Itinerário religioso - itinerário turístico
}

The Camino de Santiago (the Way of St. James) in Gaia. Religious Itinerary Tourist Itinerary

El Camino de Santiago en Gaia. Itinerário Religioso - Itinerarío Turístico http://dx.doi.org/10.18472/cvt.16n3.2016.1074

Graça Nunes da Ponte 〈graca_np@yahoo.com > Universidad de Vigo (Uvigo), Campus de Ourense, Espanha.

María de la Cruz del Río Rama 〈delrio@uvigo.es > Universidad de Vigo (Uvigo), Campus de Ourense, Espanha. José Álvarez-García 〈pepealvarez@unex.es > Universidad de Extremadura (UEX), Campus de Cáceres, Espanha.

CRONOLOGIA DO PROCESSO EDITORIAL

Recebimento do artigo: 28-jul-2015

Aceite: 04-out-2016

FORMATO PARA CITAÇÃO DESTE ARTIGO

PONTE, G. N. da; RAMA, M. C. del R.; ÁlVAREZ-GARCíA, J. O Caminho de Santiago em Gaia. Itinerário religioso - itinerário turístico. Caderno Virtual de Turismo. Rio de Janeiro, v. 16, n. 3, p. 106-122, dez. 2016.

$$
\text { REALIZAÇÃO }
$$

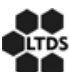

APOIO INSTITUCIONAL

COPPE

UFR]

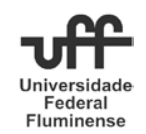

EDIÇÃO

PATROCÍNIO

IRTOR

(1) 


\section{RESUMO}

$\mathrm{Na}$ atual conjuntura, o turismo religioso tem adquirido uma importância crescente, em que se registram cada vez mais peregrinações. O caminho de peregrinação de Santiago, para além da sua inegável vertente religiosa e cultural, é também uma realidade turística, assumindo uma capacidade de contribuir estrategicamente para o desenvolvimento regional e local. Um dos caminhos que conduz os peregrinos até Santiago de Compostela - o Caminho Central Português - atravessa toda a cidade de Vila Nova de Gaia, ao longo de cerca de 15 quilômetros. Esse pequeno trajeto é o objeto de estudo deste trabalho, em que a sua análise implicou não só uma pesquisa bibliográfica, mas também uma pesquisa de campo no sentido de detectar a viabilidade de revitalizar este tipo de itinerário, de forma a tornar a peregrinação mais aprazível e, simultaneamente, fornecer ao peregrino toda a informação que ele necessita tendo ainda a possibilidade de conhecer um pouco da cidade por onde está passando. São ainda apresentadas algumas ações de dinamização e promoção que podem contribuir para incentivar um turismo sustentável e responsável.

Palavras-chave: Caminho de Santiago. Turismo religioso. Peregrinações. Vila Nova de Gaia. Promoção..

\section{ABSTRACT}

Currently religious tourism has become increasingly important while we assist to a growing number of peregrination. The Way of Saint James (Caminho de Santiago) of peregrination, besides its undeniable religious and cultural aspects, it is also a tourist reality, assuming the ability to contribute strategically to the regional and local development. One of the paths that leads the pilgrims to Santiago de Compostela - the Portuguese Central Way - crosses the entire city of Vila Nova de Gaia, along about 15 kilometers. This short trip is the object of study in this work, in which its analysis implied not only a literature search, but also a field investigation in the sense of detecting the viability of revitalizing this type of itinerary so as to permit a peregrination quieter and simultaneously offer the peregrine all the information it need by allowing the possibility to know a little the city where he is to pass. Some revitalization and promotion actions that can contribute to the promotion of sustainable and responsible tourism are also presented.

Keywords: Way of Saint James. Religious tourism. Pilgrimages. Vila Nova de Gaia, Promotion..

\section{RESUMEN}

En la actual coyuntura, el turismo religioso ha adquirido una importancia creciente, en el que se registran cada vez más peregrinaciones. El Camino de Santiago de peregrinación, además de su innegable vertiente religiosa y cultural, también es una realidad turística, asumiendo la capacidad de contribuir estratégicamente para el desarrollo regional y local. Uno de los caminos que conducen a los peregrinos a Santiago de Compostela - el Camino Portugués Central - atraviesa toda la ciudad de Vila Nova de Gaia, a lo largo de unos 15 kilómetros. Este pequeño trayecto es el objeto de estudio en este trabajo, en el que su análisis implicó no solo una búsqueda bibliográfica, sino también, una investigación de campo en el sentido de detectar la viabilidad de revitalizar este tipo de itinerario de forma que permita una peregrinación más tranquila y simultáneamente ofrecer al peregrino toda la información que necesita permitiendo la posibilidad de conocer un poco la ciudad por donde está a pasar. Se presentan también algunas acciones de dinamización y promoción que pueden contribuir a la promoción del turismo sostenible y responsable.

Palavras clave: Camino de Santiago. Turismo religioso. Peregrinaciones. Vila Nova de Gaia. Promoción. 


\section{Introdução}

O tema apresenta Muito se fala ultimamente nos Caminhos de Santiago, e, nos últimos anos, as entidades públicas parecem ter despertado para esse fenômeno cultural que, de ano para ano, conduz cada vez mais peregrinos a Santiago de Compostela (Galícia - Espanha).

Em Portugal, o Turismo Religioso representa cerca de 10\% do total de receitas geradas em turismo, de acordo com estimativas da Confederação do Turismo Português, e, embora Fátima e Braga liderem a lista dos locais mais procurados, quer o Norte quer o Sul têm um grande potencial, em termos de patrimônio religioso, material e imaterial, que lhes conferem condições para integrar em itinerários turísticos da fé e da espiritualidade (PEDRO, 2014).

O Plano Estratégico Nacional do Turismo (Pent) de Portugal para 2013-2015, aprovado em 2007, define dez produtos estratégicos de acordo com os recursos e os fatores distintivos de Portugal tendo também em conta o seu potencial de crescimento futuro. O turismo religioso integra-se em um desses produtos Touring - Turismo Cultural e Religioso, e para esse produto estratégico são previstas algumas ações, como reforçar os circuitos turísticos religiosos e culturais, valorizar peregrinações e itinerários religiosos, como é o caso do Caminho Português Central de Santiago, referindo ainda que "importa, igualmente, formatar itinerários que valorizem e integrem esse patrimônio e incentivar a criação de experiências de turismo rural que qualifiquem e diversifiquem as ofertas" (PENT, 2013, p. 2174).

Embora Fátima seja o produto estrela do turismo religioso em Portugal, já se nota um interesse por parte de alguns municípios ${ }^{1}$ portugueses na dinamização do Caminho de Santiago, nomeadamente na colocação de sinalização, não só para proporcionar segurança e orientação aos peregrinos, mas também para que conheçam a sua história local e os seus atrativos turísticos.

Vários são os Caminhos de Santiago, e um desses Caminhos - o Caminho Central Português - inicia em Lisboa e passa por Vila Nova de Gaia (Portugal). E é precisamente nesse trajeto, que atravessa Gaia, que incide o objeto deste artigo, onde se pretende apurar de que forma pode um itinerário de índole religiosa, constituir simultaneamente um itinerário turístico. "O Caminho de Santiago em Gaia - Itinerário Religioso, Itinerário Turístico" constitui simultaneamente um trabalho de investigação e apresentação de uma proposta de dinamização e promoção desse trajeto, que pretende contribuir para a melhoria dos acessos percorridos pelos peregrinos, bem como da sinalização e da sua divulgação e promoção, capaz de fornecer aos peregrinos todas as informações necessárias relativas não só ao trajeto, mas também dos serviços de que dispõe ao longo do Caminho e pontos de interesse alusivos ao patrimônio cultural, histórico e ambiental.

\section{Turismo religioso, peregrinações e itinerários Turismo Religioso}

Desde tempos remotos que a religião move multidões, pessoas crentes e devotas que se deslocam quer por devoção, quer pelo prazer de visitar patrimônio religioso ou locais ditos sagrados ou de fé. A evolução dos destinos religiosos, sobretudo aqueles que representam grandes centros de peregrinações (santu-

\footnotetext{
1 Portugal tem uma estrutura administrativa e organização territorial dividida em 18 distritos e duas regiões autônomas, Açores e Madeira. Os distritos e as regiões autônomas se subdividem em 308 municípios ou conselhos. Normalmente um distrito tem o nome do povoado maior ou cidade, ou, pelo menos, do seu povoado ou cidade mais importante historicamente.
} 
ários), tem revelado uma grande influência dos espaços envolventes, permitindo que a fruição de outros valores relacionados com patrimônio cultural, natureza e paisagens se combinem com os do turismo religioso (ALMEIDA, 2013).

De acordo com Jaluska e Junqueira (2012), entre os diversos segmentos turísticos, o turismo religioso caracteriza-se pelos deslocamentos motivados pela fé, por meio de romarias ou peregrinações, ou pelo interesse em adquirir conhecimento de alguma outra cultura religiosa, através de visitas a templos, santuários, lugares histórico-culturais, ou até mesmo da realização de rituais ou participação em eventos característicos de determinada religião.

Josep-Enric Parellada², citado por Marques (2010a, p. 122), dá uma definição de turismo religioso, em que considera "aquele tipo de turismo que tem como motivações a visita a lugares sagrados (santuários, conventos, mosteiros, igrejas, ermidas, capelas, catedrais) ou a participação em festas religiosas (Semana Santa em Sevilha, por exemplo) para descobrir o genius loci, ou seja, a essência religiosa, a mensagem transmitida, pela beleza histórica e artística. Isso não exclui, e até inclui muitas vezes, a oração e a celebração de sacramentos".

Do resultado dessa definição, Marques (2010b) distingue três tipos de locais capazes de atrair o turismo religioso: os santuários de peregrinação; os espaços religiosos que têm um patrimônio cultural, histórico e artístico significativo; e as grandes reuniões de grupos religiosos e celebrações também de caráter religioso. Para o presente estudo, interessa o primeiro tipo, que envolve o ato de peregrinar.

\section{Peregrinações}

Conforme refere Marques (2010b), a peregrinação é uma das mais antigas tradições religiosas da humanidade. Jorge (s/d), considera que os peregrinos são pessoas que estão sempre em movimento, e que passam por territórios alheios procurando uma interação, clareza, um destino para o próprio espírito, para que este possa apontar o melhor caminho a seguir. Segundo este autor e peregrino, as peregrinações realizam-se por motivos religiosos a um lugar considerado, de certa forma, sagrado ou milagroso, e constituem uma forma de culto religioso adotado em quase todas as religiões.

Embora as peregrinações se realizem por motivos religiosos, é certo que nos dias de hoje estão integradas no contexto do turismo religioso, não só pelo fato de envolver uma deslocação, mas também pelos elementos que vão "distraindo" o peregrino ao longo do caminho, como monumentos que despertam a sua atenção e vontade de visitar, relevantes pontos de interesse em determinadas regiões, a própria gastronomia típica por onde vai passando e o levam a interagir com as populações locais e seus costumes e tradições.

Marques (2010b), considera que os trilhos de peregrinação a Santiago estão direcionados ao turista em geral, distinguindo vários tipos: o turista que peregrina movido pela fé, entendendo a caminhada como um veículo de aproximação com Deus e consigo próprio, visitando, por isso, outros santuários, orando e encarando a sua viagem como penitência, ou como modo de louvor pela sua crença; o turista aventureiro, amante da natureza, que gosta de andar a pé e vê nos Caminhos de Santiago uma oportunidade de se

\footnotetext{
2 Josep-Enric Parellada é diretor do Departamento de Pastoral de Turismo, Santuários e Peregrinações da Conferência Episcopal Espanhola, e a definição referida de turismo religioso está no texto intitulado "El Turismo Religioso - sus perfiles" e que foi apresentado nas Jornadas da Pastoral do Turismo, em Ávila, em 2009.
} 
aproximar da paisagem natural e humana, bem como de estreitar laços com velhas ou novas amizades; e o turista que pode peregrinar com devoção, mas que aproveita a viagem para sair da realidade comum e alargar horizontes, aventurar-se e tirar dessa experiência prazer pelas várias dimensões que essa "peregrinação turística" lhe proporciona.

\section{Itinerários}

A mobilidade é um conceito que está profundamente ligado ao turismo. Segundo Ferreira, Aguiar e Monteiro (s/d), os itinerários surgem como uma das respostas possíveis ao constante desafio de criação de novos produtos turísticos, dada a sua capacidade de atrair visitantes, contribuir para o aumento da visibilidade do seu patrimônio material e imaterial e para a melhoria da imagem do destino.

De acordo com a Carta dos Itinerários Europeus (ICOMOS, 2008), elaborada pelo Comitê Científico Internacional dos Itinerários Culturais (CIIC) "um itinerário cultural é uma via de comunicação terrestre, aquática, mista ou outra, fisicamente definida, com uma dinâmica e funções históricas próprias, a serviço de um objetivo concreto e determinado". Cita também que essa via deve ser um espaço de intercâmbios culturais, multidimensionais e recíprocos, capaz de gerar uma grande riqueza patrimonial e fomentar relações históricas entre povos distintos.

Em 1987, o Caminho de Santiago foi declarado, pelo Conselho da Europa, como Primeiro Itinerário Cultural da Europa, na mesma altura que foi lançado o Programa dos Itinerários Culturais Europeus pelo Conselho da Europa, cuja promoção tem uma tripla finalidade: (1) Tornar mais visível, valorizar e pôr em prática uma identidade cultural comum aos cidadãos europeus; (2) Salvaguardar e destacar o patrimônio cultural europeu como fator de melhoria do modo de vida e como causa de desenvolvimento social, econômico e cultural; (3) Oferecer aos cidadãos novas possibilidades dos seus tempos livres, dando um lugar de destaque ao turismo cultural e respectivas práticas (EUROPEAN INSTITUTE OF CULTURAL ROUTES, 2002).

Em 1997 foi criado o Instituto Europeu dos Itinerários Culturais, destinado a acolher o Programa dos Itinerários Culturais, acompanhar os promotores dos itinerários culturais já elegidos, ajudar os portadores de novos projetos a pôr em prática as suas iniciativas e a difundir todas as informações sobre o programa (EUROPEAN INSTITUTE OF CULTURAL ROUTES, 2002). Um itinerário cultural não é, em si mesmo, um itinerário turístico, mas pode também constituir uma forma de dinamização turística em vários níveis, desde a natureza ao patrimônio material ou imaterial, contribuindo para trazer vários benefícios para as populações nelas envolvidas (PINHEIRO, 2007).

Os itinerários culturais permitem ainda promover um turismo sustentável e responsável, canalizar os fluxos turísticos e contribuir para a conservação dos monumentos. Ao mesmo tempo, o desenvolvimento de um itinerário temático não necessita de um orçamento muito elevado, nem de grandes investimentos (MAAK, 2009).

\section{Santiago - a Origem do Culto}

No Campus Stellae - de onde se crê derivar a palavra Compostela - foi erguida uma capela para proteger 
a tumba do apóstolo que se tornou um símbolo da resistência cristã aos ataques dos mouros (CEG, s/d). Ao saber do sucedido, o rei Afonso II (rei das Astúrias), desloca-se àquele local e manda construir um mosteiro que cuidasse e regulasse o culto ao apóstolo. Assim, Compostela começou por ter um mosteiro, um santuário martirial, uma igreja para o culto e um batistério. Também nessa altura, a diocese de Iria Flavia transferiu-se para aquele novo local, levando à construção de edifícios episcopais. A igreja mandada construir por Afonso II, transformou-se em basílica com Afonso III, tendo sido destruída por Almançor (em 996) e reconstruída até a grande catedral românica (FERNANDES, 2014).

É a partir do ano 1000 que as peregrinações a Santiago se tornam mais populares, tornando-se essa cidade um dos principais centros de peregrinação cristã. Nessa altura, começam ainda a surgir os primeiros relatos de peregrinos a Compostela. Naquele momento, a Europa cristã apresentava um notável progresso baseado em um forte crescimento demográfico, na extensão das áreas cultivadas e no aumento da produtividade (GIL; RODRIGUES, 1990). E progressivamente ia amadurecendo em Santiago de Compostela a criação de um centro religioso capaz de concorrer em celebridade com Roma ou Jerusalém.

Otero (2009) refere que em Portugal, desde o século XII até aos dias de hoje, os peregrinos portugueses não deixaram de ir a Santiago, desde vilas a cidades, grandes ou pequenas, próximas ou distantes, como Braga, Porto, Coimbra, Lisboa, Santarém, Óbidos e Évora. Com os peregrinos vieram mercadores, feirantes, médicos e curandeiros, beneméritos, filósofos, clero, nobreza e o exército. Para recuperar essa velha forma de caminhar e esses velhos caminhos, tem que se refazê-los, inventá-los de novo, criar novas rotas, já não tanto para a peregrinação, mas também para o desporto e para o turismo.

Solla (2006) reforça essa ideia referindo que nos últimos anos as peregrinações a Compostela adquirem uma grande importância, e hoje em dia constituem um produto turístico em que a religião cada vez tem menos relevância. Canavarro (2010) refere que a peregrinação ao Túmulo de Santiago é como uma nova bandeira que desde o seu início assina a identidade europeia que se procura erguer como afirmação de apogeu ocidental na transição da Idade Média para a Idade Moderna. Ao longo dessa época e da contemporânea seguiram-se períodos de crise, voltando a ganhar mais presença no final do século passado, sendo hoje em dia, no limiar do século XXI, um caminhar de dimensão ainda mais internacional.

\section{Os Caminhos de Santiago}

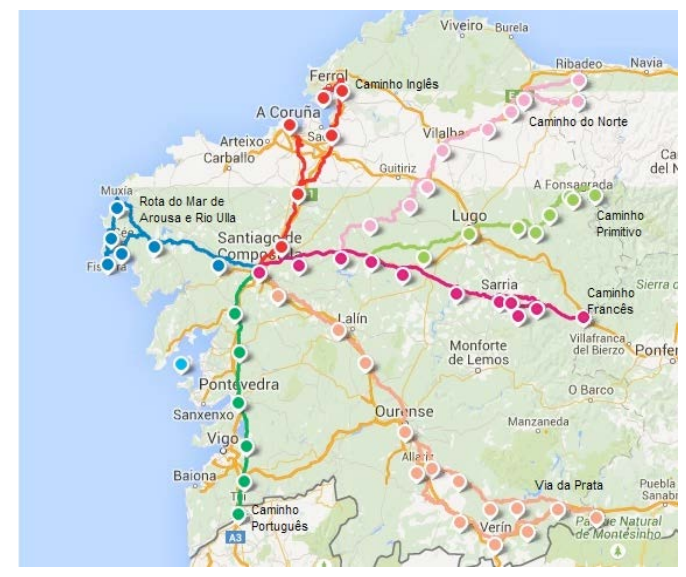

\section{Figura 1 - Os Caminhos de Santiago na Galícia Fonte: Xacobeu Galícia}

O Caminho de Santiago não é um só caminho, mas sim um conjunto de rotas que se espalham por toda a Europa e que acabam por se entroncar nos caminhos espanhóis, até chegarem ao destino sagrado - Santiago de Compostela.

De todas essas rotas, destacam-se as mais conhecidas, localizadas na Galícia (Figura 1) e que estão 
diretamente ligadas à chegada a Santiago de Compostela, ou que se juntam a estas durante o percurso, são elas, seguindo os ponteiros do relógio: o Caminho Inglês, o Caminho do Norte, o Caminho Primitivo, o Caminho Francês, a Via da Prata, o Caminho Português, e a Rota Mar de Arousa e Rio Ulla (ou Marítimo Fluvial). Para além dessas rotas existe ainda o Caminho de Finisterra que faz a ligação entre a cidade de Santiago e Finisterra. Esses caminhos que acabam por entroncar aos caminhos espanhóis espalham-se por toda a Europa (CEG, s.f.).

De todos esses caminhos, interessa realçar, para o presente estudo, o Caminho Português, onde se enquadra o Caminho Central, onde, por sua vez, se integra o Caminho de Santiago em Gaia.

\section{O Caminho Português}

Há vários Caminhos em Portugal, e a sua marcação é um fenômeno recente, que só nos últimos anos é que associações e entidades competentes começaram a marcar e a definir os percursos. Existem relatos de peregrinos que viajaram para Santiago do sul do país, por isso sabe-se que existem esses caminhos (CEG, s.f.). Em 2013 foi publicada uma nota de imprensa que informa que a Câmara Municipal de Nisa iria implementar um projeto de sinalização e marcação do Caminho de Santiago na sua passagem por este Concelho. Esse itinerário integra o Caminho Português do Interior, também conhecido como Caminho Português de Leste, que inicia em Tavira, no Algarve, e entra na Galícia por Chaves, ligando-se ao Caminho Sanabrês (prolongamento da Via da Prata) e seguindo por este até Santiago ${ }^{3}$.

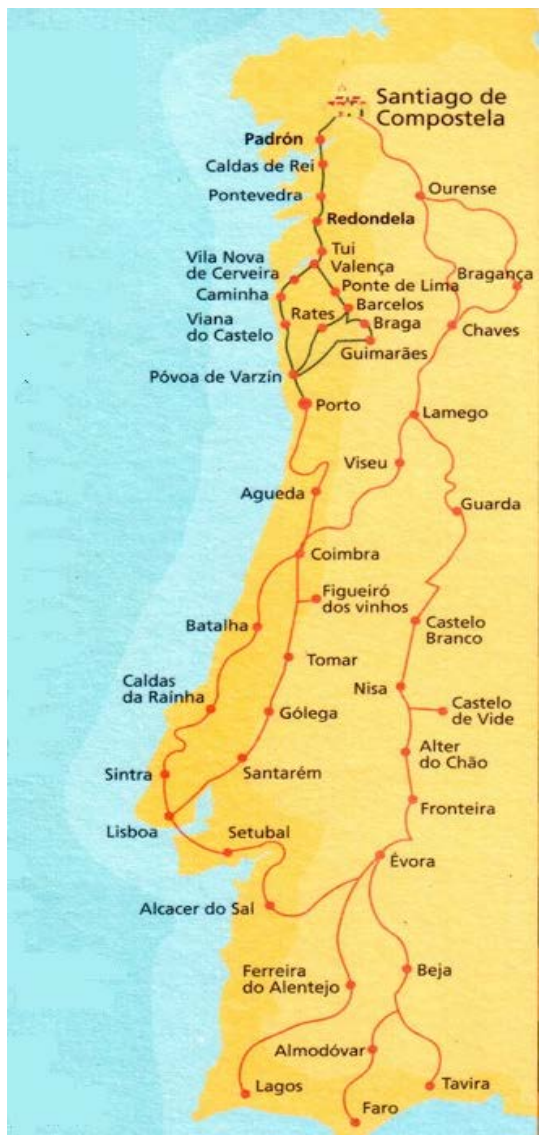

\section{Figura 2 - Caminhos Portugueses Fonte: Xacobeu Galícia}

De Lisboa parte o Caminho Central de Santiago. Segue em direção a Coimbra (existindo duas variantes, uma por Tomar - que corresponde até Santarém ao Caminho do Tejo - outra por Leiria). Em Coimbra existem duas alternativas, pelo Caminho do Interior (por Viseu e Chaves que sai de Portugal em Feces de Abaixo e se junta à Via da Prata em Verin), ou continuando pelo Caminho Central (em direção ao Porto).

A partir do Porto segue também o Caminho da Costa, que ganhou relevância a partir da Idade Moderna, sobretudo a partir do século XVIII, pois era utilizado pelas populações costeiras e pelos que desembarcavam nos portos marítimos. Assim, este percurso que parte do Porto passa pelos concelhos de Matosinhos, Maia, Vila do Conde, Póvoa do Varzim, Esposende, Viana do Castelo, Caminha, Vila Nova de Cerveira e Valença. Esse Caminho Português da Costa, considerado uma derivação do Caminho Central, encontra-se com este em Tui (Caminho Português da Costa).

3 Câmara Municipal de Nisa, Nota de Imprensa n. 04, de 14 de fevereiro de 2013, disponível em 〈http://www.cm-nisa.pt/informacaomunicialpublicacoes/imagensnotasdeimprensa/2013/nota_04_2013.pdf〉. Acesso em: 26 abr. 2015. 


\section{Estatísticas dos peregrinos}

Quem mantém vivos os caminhos são os peregrinos, e alguns indicadores como o seu número, que meios utilizam, as suas motivações, que caminho percorreram, entre outros, ajudam a compreender a importância dos Caminhos de Santiago no âmbito do presente estudo. Os dados que se seguem foram obtidos por meio das informações estatísticas do Posto de Acolhimento de Peregrinos da Catedral de Santiago de Compostela, publicadas no seu site (Oficina de Acogida al Peregrino), tendo em conta os peregrinos que ali foram recebidos nos últimos anos até 2014.

\section{a) Número de peregrinos}

A Figura 3 demonstra que o número de peregrinos que se deslocam para Santiago de Compostela tem aumentado ao longo dos anos, não se considerando o ano de 2010 por ter sido Ano Santo e, naturalmente, os valores são diferentes, já que em anos de Jacobeu (quando o dia 25 de julho, Dia de Santiago, coincide com um domingo) o santuário de Santiago de Compostela tem uma afluência muito maior.

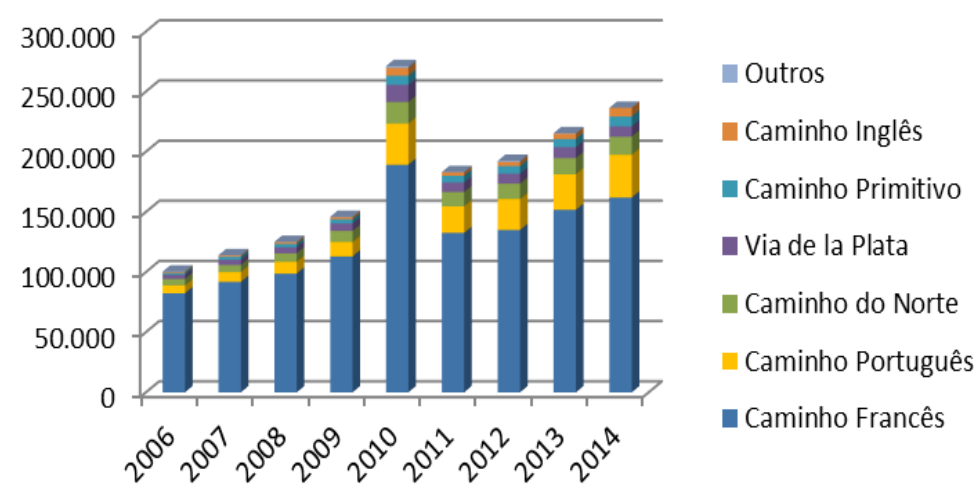

Figura 3 - Número de peregrinos que chegam a Santiago e os caminhos que percorrem Fonte: Elaboração própria a partir de dados do Posto de Acolhimento ao Peregrino (Oficina de Acogida al Peregrino)

\section{b) Caminhos mais percorridos}

O Caminho Francês é claramente o itinerário mais percorrido pela maioria dos peregrinos (cerca de $70 \%$ ), sendo o Caminho Português o segundo mais percorrido (cerca de 14\%). Também é verdade que, nos últimos anos, se têm verificado um crescimento do número de peregrinos que chegam a Compostela por outros itinerários, embora a tendência se mantenha. Sendo cerca de $16 \%$ dos peregrinos os que escolhem os restantes caminhos para a sua peregrinação até Santiago (Figura 3).

\section{c) Meio utilizado}

O maior número de chegadas a Santiago de Compostela é a pé, que é a forma mais tradicional de se peregrinar. Essa tendência mantém-se relativamente estável ao longo dos anos. 
Tabela 1 - Peregrinos que chegam a Santiago segundo o meio utilizado

\begin{tabular}{|l|c|c|c|c|c|c|c|c|c|}
\hline & 2006 & 2007 & 2008 & 2009 & 2010 & 2011 & 2012 & 2013 & 2014 \\
\hline Pé & 81.783 & 93.953 & 103.669 & 120.605 & 237.852 & 153.065 & 164.778 & 188.191 & 210.942 \\
\hline Bicicleta & 18.289 & 19.702 & 21.143 & 24.892 & 32.926 & 29.949 & 27.407 & 26.646 & 25.325 \\
\hline Cavalo & 283 & 364 & 290 & 341 & 1315 & 341 & 281 & 977 & 1.520 \\
\hline
\end{tabular}

Fonte: Elaboração própria a partir de dados do Posto de Acolhimento ao Peregrino (Oficina de Acogida al Peregrino)

\section{d) Motivações}

Há um grande número de pessoas que peregrinam rumo a Santiago por motivos exclusivamente religiosos (Figura 4). Mas o maior número de pessoas são as que apresentam outras razões paralelas às motivações religiosas, ou seja, que para além da religião, outros fatores influenciam a decisão de realizar a peregrinação, tais como razões culturais, espírito de aventura e procura de sensações, de aventura e lazer. Em minoria, estão os que fazem o Caminho por motivos não religiosos, movidos por um misto de curiosidade e aventura, e vontade de conhecer esse Caminho tão conhecido e tão histórico.

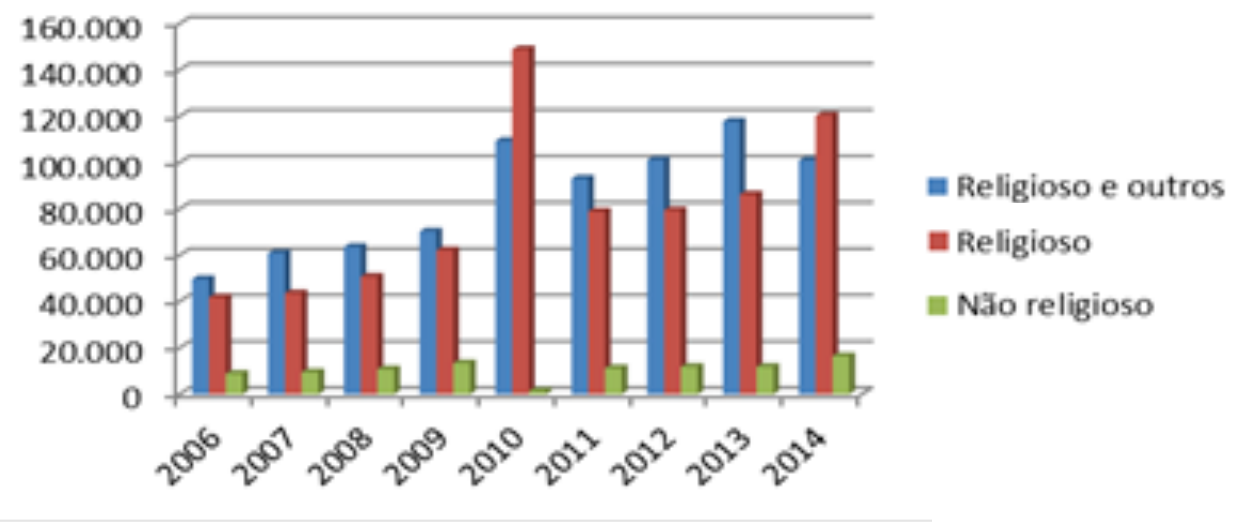

Figura 4 - Número de peregrinos que chegam a Santiago segundo o motivo Fonte: Elaboração própria a partir de dados do Posto de Acolhimento ao Peregrino (Oficina de Acogida al Peregrino)

\section{e) Proveniência}

A Tabela 2 apresenta o número de peregrinos segundo o local onde iniciam a sua peregrinação até Santiago. De todos os locais apurados no relatório estatístico efetuado pelo Posto de Acolhimento ao Peregrino de Santiago de Compostela (quase 200), foram selecionadas apenas algumas cidades portuguesas onde os peregrinos iniciam o seu percurso através do Caminho Central Português, algumas ao sul do Porto, outras ao norte (e Tui, sendo espanhola, é também um importante ponto de partida e de passagem do Caminho Central Português).

Pode, assim, observar-se que Porto é a cidade portuguesa de onde partem mais peregrinos, mas logo a seguir é Lisboa, o que, para o estudo em questão, é importante ter a noção da existência da probabilidade de um número crescente de peregrinos passar por Vila Nova de Gaia. Na verdade, não há um local definido para começar o Caminho, no caso do Caminho Português, é notória a preferência por um maior 
número de peregrinos de iniciar o seu caminho em Tui e no Porto, havendo uma tendência crescente em fazer o mesmo a partir de Lisboa.

Tabela 2 - Peregrinos que chegam a Santiago segundo a proveniência

\begin{tabular}{|c|c|c|c|c|c|c|}
\hline & 2009 & 2010 & 2011 & 2012 & 2013 & 2014 \\
\hline Tui & 4.169 & 18.121 & 7.720 & 8.436 & $9 \cdot 394$ & 11.816 \\
\hline Porto & 3.236 & 5.694 & 6.539 & 7.641 & 8.859 & 10.395 \\
\hline Lisboa & 449 & 718 & 647 & 977 & 1.067 & 1.435 \\
\hline Ponte de Lima & 456 & 709 & 828 & 901 & 966 & 1.315 \\
\hline Rates, S. Pedro & & & & 343 & 635 & 531 \\
\hline Braga & 228 & 271 & 255 & 333 & 399 & 565 \\
\hline Barcelos & & & & 245 & 544 & 542 \\
\hline Viana do Castelo & & & & 111 & 161 & 184 \\
\hline Guimarães & & & & 61 & 178 & 282 \\
\hline Póvoa do Varzim & & & 41 & 54 & 75 & 60 \\
\hline Coimbra & & & & 47 & 123 & 157 \\
\hline Esposende & & & & 12 & 38 & 24 \\
\hline Aveiro & & & & 4 & 29 & 39 \\
\hline Resto de Portugal & 1.563 & 2.984 & 2.832 & 2.660 & 1.602 & \\
\hline
\end{tabular}

Fonte: Elaboração própria a partir de dados do Posto de Acolhimento ao Peregrino (Oficina de Acogida al Peregrino)

\section{A tutela do Caminho}

Em Portugal não há uma entidade institucional responsável pela coordenação, gestão e promoção do Caminho, mas existem diversas associações e confrarias que, voluntariamente, vão fazendo esse trabalho, sobretudo em termos de levantamento, marcação e sinalização, em um trabalho mais ou menos direto com o poder local (MARQUES; FERREIRA, 2012). Essas associações também apoiam os peregrinos que pretendem realizar o percurso, providenciando mapas, credenciais e qualquer apoio logístico de que precisem. Na sua maioria tem uma lista de associados e organizam passeios anuais (CEG, s/d). Em Vila Nova de Gaia existe a Confraria de Santiago da Paróquia de S. Salvador de Grijó, fundada em 2012, sediada em Gaia.

\section{O Caminho de Santiago em Gaia}

\section{Enquadramento geográfico}

O município de Vila Nova de Gaia, em nível nacional, localiza-se no noroeste de Portugal, pertence ao distrito do Porto e faz parte da Região Norte (NUTS II) sendo o maior da Área Metropolitana do Porto ou Grande Porto (NUTS III). Situa-se à margem sul do Rio Douro, ocupa uma área de $168 \mathrm{~km} 2$ e tem cerca de 302.295 habitantes (Gaiurb). O território municipal é limitado a Oeste pelo Oceano Atlântico 
(tem uma faixa costeira de cerca de 17 quilômetros), a Norte e Nordeste pelo Rio Douro, que o separa dos concelhos do Porto e Gondomar, a Sul, junto à orla costeira, confronta com Espinho, e na zona interior, com Santa Maria da Feira.

\section{Metodologia}

A análise do percurso do Caminho de Santiago em Gaia foi realizada por meio de trabalho de campo que consistiu em uma investigação in loco com o intuito de fazer o levantamento dos seguintes elementos: estado das vias, o nível de dificuldade e as condições de segurança; definir o itinerário; identificar os pontos de interesse capazes de captar a atenção dos peregrinos; analisar a sinalização do trajeto; averiguar os serviços que existem ao longo do trajeto e que poderão ser úteis ao peregrino, desde cafés, restaurantes, comércio, alojamento, entre outros (neste trabalho, considerou-se apenas o alojamento direcionado a peregrinos); obter informações sobre o Albergue de peregrinos em Grijó, bem como sua taxa de ocupação; conhecer a distância e o tempo médio que o peregrino levará para percorrer o trajeto.

Além de recolher todos esses dados, foi feito um levantamento fotográfico em todo o itinerário, no sentido de registrar as condições dos acessos, o estado da sinalização e outros pontos que possam ser necessários para a investigação. O levantamento no terreno para análise dos pontos fundamentais que compõem o Caminho de Santiago em Vila Nova de Gaia foi realizado por fases ou etapas, de forma a facilitar a leitura dos dados. Assim, neste estudo, o percurso está dividido em cinco fases: C1: U.F. de Grijó e Sermonde; C2: U.F. de Serzedo e Perosinho; C3: Freguesia de Canelas; C4: U.F. de Mafamude e Vilar do Paraíso (até à Rotunda de Santo Ovídeo); C5: da Rotunda de Santo Ovídeo à Ponte Luís I (abrangendo a U.F. de Mafamude e Vilar do Paraíso e U.F. de Santa Marinha e São Pedro da Afurada).

\section{Análise Swot do Caminho de Santiago em Gaia}

A análise que se segue foi realizada com o intuito de compreender os fatores que podem influenciar a dinamização e implementação do Caminho de Santiago que passa por Gaia com base nas ameaças, pontos fortes, pontos fracos e oportunidades, e tendo em consideração o ambiente externo e interno a todo esse cenário. Pretende-se que a análise desses dados contribua para a elaboração da proposta de implementação e dinamização do Caminho de Santiago em Gaia, nomeadamente no que concerne à definição de ações estratégicas e operacionais. 
Tabela 1 - Análise Swot do Caminho de Santiago em Gaia

\begin{tabular}{l} 
Análise Interna \\
\hline Pontos fortes \\
- Percurso sinalizado na quase totalidade \\
- Dinamização do interior das freguesias fazendo com que o comércio local se beneficie da passagem \\
de alguns peregrinos \\
- Existência de um albergue de peregrinos \\
- Existência da Confraria dos Caminhos de Santiago de S. Salvador de Grijó \\
- Uma grande parte do Caminho passa por zonas rurais \\
- Possibilidade de adquirir a credencial do peregrino no Mosteiro de Grijó \\
- A Serra de Negrelos é uma Unidade Operativa de Planejamento e Gestão (UOPG) prevista no Plano \\
Diretor Municipal \\
\hline Pontos fracos \\
\hline - A sinalização existente é feita à base de setas amarelas pintadas, que se deterioram com mais \\
facilidade \\
- Sinalização incorreta em algumas zonas \\
- A Serra de Negrelos, por onde passa o caminho, é bastante isolada, sem qualquer segurança, e tem \\
lixo doméstico \\
- Escassez de patrimônio monumental e cultural \\
- Informação insuficiente sobre o percurso do Caminho que atravessa Gaia \\
- Inexistência de dados estatísticos acerca do número de peregrinos que passa por Gaia \\
\hline \multicolumn{1}{c}{ Análise Externa } \\
\hline Oportunidades \\
\hline - Integra o Caminho Português, o segundo Caminho de Santiago mais percorrido \\
- Depois da nova revisão do Pent, o turismo religioso passou a enquadrar um dos dez produtos \\
estratégicos \\
- Interesse e preocupação de Associações ligadas ao Caminho em realizar a manutenção da sinalização \\
deste, revelando, de uma forma gratuita, uma preocupação constante em relação ao Caminho \\
- Evolução das Tecnologias de Informação e Comunicaçáo (TICs) \\
- Interesse por parte da Autarquia em dinamizar o itinerário do Caminho de Santiago que passa em \\
Gaia \\
- Existência de fundos comunitários que podem ser utilizados em prol da valorização dos caminhos \\
Ameaças \\
- Um grande percentual de peregrinos começa o Caminho a partir do Porto \\
- Ausência de uma entidade responsável pela tutela do Caminho
\end{tabular}

Fonte: Elaboração própria

\section{Proposta de dinamização}

A presente proposta pretende implementar o itinerário que corresponde ao trajeto do Caminho Central de Santiago que passa em Gaia, no sentido de, não só conhecer a cidade de Gaia e o seu patrimônio natural, paisagístico, histórico e cultural, respondendo, dessa forma, às diretrizes do Plano Estratégico Nacional do Turismo, como também contribuir para a melhoria dos acessos dotando o Caminho de condições capazes de responder às necessidades dos peregrinos. Pretende-se assim, melhorar a sinalização seguindo as recomendações existentes sobre os Caminhos de Santiago, e propor a sua promoção utili- 
zando as ferramentas que dispomos atualmente, de modo a reforçar o papel do município de Vila Nova de Gaia como agente de promoção e proteção do Caminho Central Português.

\section{a) Sinalização}

Em 2008 foram publicadas, na Espanha, uma série de normas por meio da Nota de Serviço 1/2008 denominada "Señalizacion del Camino de Santiago" no sentido de melhorar a qualidade, segurança e homogeneidade dos itinerários históricos transitados por meios não motorizados (a pé, de bicicleta, a cavalo), e diminuir o conflito nos pontos de contato com as estradas, e onde define critérios de implantação, as características dos sinais e dos seus materiais (DIRECCIÓN GENERAL DE CARRETERAS, 2008).

Desde que os Caminhos de Santiago foram designados como Itinerário Cultural do Conselho da Europa, em 1987, beneficiam de um logotipo específico com as cores da Europa que permite a identificação e reconhecimento dos itinerários compostelanos em escala continental. A sua função é a identificação do caminho até Compostela, sendo um logotipo posicional e não direcional. Tem acontecido por vezes a sua má colocação em alguns territórios, tornando-se confuso para os caminhantes que não sabem que caminho seguir. Para fazer face a essas incoerências, a ACIR Compostelle (Association de Coopération Interrégionale - Les Chemins de Saint-Jacques de Compostelle) realizou um dossier de recomendações para acompanhar projetos de marcação dos caminhos conducentes a Santiago de Compostela, de forma a dotar esses caminhos de uma sinalização europeia coerente (ACIR, 2009). Desde que o Caminho de Santiago foi eleito como Itinerário Cultural Europeu (em 1987) pelo Conselho da Europa, foi selecionado um emblema como um símbolo ser utilizado em todos os seus trajetos: a concha de vieira.

Em Vila Nova de Gaia, esse tipo de sinalização é ainda uma lacuna, o trajeto do Caminho está sinalizado com setas amarelas pintadas nos mais variados sítios, o que exige uma maior manutenção já que, ao longo dos tempos vão desaparecendo, estando algumas localizadas em locais de reduzida visibilidade. Apenas em Perosinho existe sinalização desse tipo, desde 2011, mas o logotipo está incorretamente colocado.

Assim, face a todo o exposto, e no sentido de implementar uma sinalização uniforme do Caminho Central de Santiago que passa em Gaia, propõe-se o seguinte: (1) colocação de um painel informativo na entrada do Mosteiro de Grijó (onde inicia o trajeto), com o mapa do caminho e seu itinerário, altimetria, contatos úteis e informações úteis; (2) colocação de sinais simultaneamente posicionais e direcionais, em zonas de cruzamentos, entroncamentos e bifurcações; (3) colocação de sinais posicionais e informativos de patrimônio que se localiza no Caminho.

\section{b) Implementação de folheto informativo}

Elaboração de um folheto com informações de todo o itinerário que vai desde o Mosteiro de Grijó à Ponte Luís I, com informações sobre o Concelho, localização do Albergue, pontos de interesse e contatos úteis. No fundo, um pequeno guia dirigido aos peregrinos que atravessam Gaia pelo Caminho de Santiago.

\section{c) Implementação do carimbo do Município}

Implementar o carimbo oficial do município de Gaia de modo a carimbar o passaporte do peregrino, quando solicitado, disponibilizando-o em vários pontos estratégicos, ou, uma vez que a Confraria da Paróquia de S. Salvador de Grijó também tem o seu carimbo disponível no Albergue, o do município deverá estar disponível nos dois postos de informação turística municipal (do Cais de Gaia e da Beira-Rio) e ainda no Atendimento Geral do município. 


\section{d) Utilização das Tecnologias de Informação e Comunicação (TICs)}

Embora o itinerário do Caminho de Santiago deva ser sinalizado de forma a ser percorrido por qualquer pessoa, mesmo sem experiência ou sem recurso a técnicas ou equipamentos de orientação (GPS, bússola, mapas, guias, etc.), nos dias de hoje, e com o advento da internet, torna-se útil e conveniente criar alternativas de pesquisa e recolha de informação. A internet representa uma excelente ferramenta de desenvolvimento da atividade turística e um meio dinâmico de acesso à informação.

Também integrados às TICs estão os Sistemas de Informação Geográfica (SIGs), que, no caso concreto, constituem uma ferramenta de grande utilidade, na medida em que permitem georreferenciar dados do percurso, podendo, dessa forma, os caminhantes descarregar esses dados para o seu smartphone ou tablet, e visualizá-los de forma dinâmica, calcular distâncias, aceder a informações diversas (pontos de interesse, serviços, contatos úteis, hiperligações com outras páginas da internet) entre outras funcionalidades.

Assim, e de forma a tirar o máximo de benefício possível das TICs, de modo a tornar acessível a um maior número de pessoas todas as informações necessárias relativas ao Caminho de Santiago que passa em Gaia, propõe-se o seguinte: (1) colocação de informação no portal do município: informação histórica, descrição do itinerário, informações sobre o Albergue de S. Salvador de Grijó, outros dados que possam ser úteis ao peregrino, mapa em ficheiro kml, criação de um código QR com ligação a todas essas informações; (2) utilização das redes sociais e criação de um blog para divulgar e promover o Caminho, bem como para fornecer todas as informações de que o peregrino possa necessitar.

\section{e) Implementação do menu do peregrino}

O chamado "Menu do Peregrino" consiste em um menu com um custo muito baixo, desenhado especialmente para os peregrinos que estão em caminhada, e têm, assim, a oportunidade de comer um prato quente que em alguns casos incluem até mesmo certas especialidades locais. Para ter acesso a esse menu é obrigatório apresentar a sua credencial, evitando, dessa forma, abusos de quem não é peregrino. Em Grijó, ao lado do Albergue, já existe um local que tem esse menu. Uma vez que o percurso em Gaia tem 15 quilômetros, teria todo o sentido em existir também esse tipo de menu na fase final do trajeto, a partir da rotatória de Santo Ovídeo, por exemplo.

\section{Considerações finais}

Embora desde tempos muito antigos que a religião move multidões, o fenômeno da religião associada ao turismo é relativamente recente. A atividade turística envolve deslocamentos, assim como a religião e as peregrinações, por motivos religiosos ou não. O turismo encontrou aqui um nicho de mercado que só nos últimos anos começou a explorar a partir do momento em que existem outros elementos que interessam também a esse tipo de turista, como a visita a monumentos, determinados pontos de interesse e até a gastronomia típica de uma região.

As peregrinações podem, hoje em dia, ser integradas ao turismo religioso. O peregrino que tem como motivação exclusivamente religiosa não é aquele que propriamente contribui para um dinamismo da atividade turística, mas já vamos assistindo a uma vontade de repetir o caminho, desta vez por outras razões, para conhecer e visitar locais que não teve oportunidade de conhecer quando peregrinava com uma motivação religiosa. 
Os Caminhos de Santiago integram-se no âmbito dos itinerários culturais, pois são constituídos a partir de vias preexistentes cujo tema consiste em chegar ao Santuário de Santiago de Compostela e, como tal, foi considerado, em 1987, como Primeiro Grande Itinerário Cultural Europeu, pelo Conselho da Europa.

Em termos de números, e de acordo com os dados já analisados neste estudo, distinguem-se três reflexões muito importantes:

- As peregrinações a Santiago têm aumentado, o que contribui para reforçar a importância crescente que o turismo religioso tem adquirido, e, como já foi referido, assume um papel estratégico no panorama do turismo atual. Esse dado permite prever uma viabilidade para desenvolver um itinerário turístico a partir de um itinerário religioso, nesse caso, o Caminho de Santiago em Gaia;

- O Caminho Português é o segundo mais percorrido, daqui advém a possibilidade de mais peregrinos passarem também por Gaia;

- Nos dois últimos anos houve um aumento de peregrinos que fizeram o caminho a partir de Lisboa e também de Coimbra. Esses peregrinos que vêm do sul vão, obrigatoriamente, passar por Gaia. Quanto mais informações tiverem ao seu dispor, mais curiosidade vão ter em conhecer a cidade por onde irão passar, dado que as referências que existem nos guias e meios de informação apenas se referem a "Grijó".

Relativamente à dinamização que se pretende para o trajeto do Caminho Central Português que passa em Gaia, elaboram-se as seguintes considerações finais:

- Este trajeto tem uma grande diversidade territorial: começa em uma zona de interior e rural, passa por uma zona florestal (Serra de Negrelos), até chegar à zona urbana e terminando junto à zona fluvial, no Centro Histórico de Gaia, junto ao Rio Douro, não esquecendo que nesta última zona o peregrino passa por aquele que é considerado o ex-libris de Gaia - o Mosteiro da Serra do Pilar, até chegar à ponte Luís I, ambos monumentos classificados como Patrimônio Mundial da Unesco (incluídos na área do Centro Histórico do Porto). Constitui um percurso fácil, de 15 quilômetros que se faz em cerca de quatro horas e meia;

- Este trajeto pode ser considerado um itinerário cultural e, como tal, permite uma dinamização turística de forma sustentável. A proposta de dinamização apresentada neste trabalho inclui a implementação de sinalização de acordo com as recomendações existentes de modo uniforme ao que já se utiliza em outros Caminhos de Santiago, entre outras ações pretende implementar um itinerário que permita não só conhecer a cidade de Gaia, como também o seu patrimônio natural, paisagístico, histórico e cultural, respondendo, dessa forma, às diretrizes do Plano Estratégico Nacional do Turismo;

- Devem ser aproveitados os instrumentos de planeamento e gestão territorial disponíveis, nesse caso o Plano Diretor Municipal, que tem um papel fundamental na revitalização do espaço. Como já foi referido neste trabalho, no caso concreto da Serra de Negrelos, prevê a sua recuperação e valorização paisagística, entre outros objetivos.

Por último, dinamizar e revitalizar o trajeto do Caminho Central Português, que passa em Gaia, irá contribuir não só para relembrar a devoção jacobita, mas também para elevar a cultura, o território, as paisagens e o patrimônio, fazendo com que um novo caminho seja descoberto. 


\section{Referências}

ACIR. Association de Coopération Interrégionale. La Signalétique au servisse dún Patrimoine - Les Itinéraires vers Compostelle, "Préconisations pour une charte signalétique du "Grand Itinéraire Culturail du Conseil de l'Europe», Acir Compostelle, Toulouse, 2009. Disponível em: 〈http://www. vialusitana.org/sinaletica/>. Acesso em: 18 dez. 2014.

ALMEIDA, S. P. Projeto de Consultadoria na área de Turismo e Lazer. Turismo Religioso - Estudo de Mercado e Comunicação, Politécnico do Porto (s/n). Prova de candidatura ao título de especialista, 2013.

CAMINHO PORTUGUÊS DA COSTA. Disponível em: 〈http://www.cm-viladoconde.pt/PageGen.aspx? WMCM_Paginald $=$ 54495 . Acesso em: 27 abr. 2015.

CANAVARRO, P. 0 Caminho de Santiago e a Peregrinação: reflexões de um europeísta, comunicação no Seminário Internacional O Caminho de Santiago e Identidade Europeia, Alvito, 2013. Disponível em: $\quad$ http://lociiacobi.eu/wp-content/uploads/2010/05/Ponencia-Alvito-Pedro-Canavarro.pdf . Acesso em: 23 abr. 2014.

CEG. Centro de Estudos Galegos. Disponível em: «ceg.fcsh.unl.pt/〉. Acesso em: 27 abr. 2015.

DIRECCIÓN GENERAL DE CARRETERAS (2008). Señalización del Camino de Santiago. Nota de servicio 1/2008, Ministerio de Fomento. Disponível em: 〈http://www.vialusitana.org/sinaletica/ 〉. Acesso em: 10 nov. 2014.

EUROPEAN INSTITUTE OF CULTURAL ROUTES. The Cultural Routes Programme of the Council of Europe, 2002. Disponivel em: 〈http://www.cultureroutes.lu/php/fo_do_downld. php? $r$ ef $=00000263 / 00000263$. pdf\&saveas $=$ presentation $\% 20-\% 20 E N$.pdf $\rangle$. Acesso em: 05 jan. 2015.

FERNANDES, P. A. Caminhos de Santiago. Secretariado Nacional para os Bens Culturais da Igreja/ Turismo de Portugal, IP (s/l), 2014.

FERREIRA, L.; AGUIAR, L.; MONTEIRO, A. Itinerários Turísticos: contributos para a construção de uma oferta inovadora e para a criação de destinos sustentáveis, (s/d). Disponível em: 〈https://cld.pt/dl/ download/42cb39a2-9d80-4eae-8f59-a9e1713d1e70/Proceedings\%20Book\%2olTC'13/Papers/ P8o13.pdf $>$. Acesso em: 05 jan. 2015.

GAIURB. Urbanismo e Habitação. Disponível em: 〈http://www.gaiurb.pt/home.htm〉. Acesso em: 27 abr. 2015.

GIL, C.; RODRIGUES, J. Pelos Caminhos de Santiago: itinerários portugueses para Compostela, Ed. Dom Quixote, Lisboa, 1990.

ICOMOS, 2008. Carta dos Itinerários Culturais. Elaborada pelo Comitê Científico Internacional dos

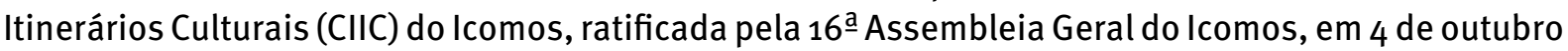
de 2008, Québec, Canadá. Disponível em: 〈http://www.icomos.org/charters/culturalroutes_sp.pdf〉.

JALUSKA, T.; JUNQUEIRA, S. A utilização dos espaços sagrados pelo Turismo Religioso e suas possibilidades como ferramenta auxiliar para o estabelecimento do diálogo entre as nações. Revista Turismo Visão e Ação - Eletrônica, v. 14, n. 3, p. 337-348, 2012. Disponível em: 〈www.spell.org.br/ documentos/download/8985>. Acesso em: 16 jan. 2015. 
JORGE, W. Pequena história de Santiago - 14 - As Peregrinações (primeira parte), (s/d). Disponível em: 〈http://www.caminhodesantiago.com.br/walter_jorge/historia_santiago/phst_14.html\#top〉. Acesso em: 11 jun. 2014.

MAAK, K. El Camino de Santiago como posible motor turísitco en zonas rurales de escasos recursos: el caso de Brandeburgo. Cuadernos de Turismo, n. 23, p. 149-171, 2009. Disponível em: 〈http://revistas. um.es/turismo/article/view/70081>. Acesso em: 05 jan. 2015.

MARQUES, J. A. M. Caminhar e Chegar - Nota sobre peregrinações, turismo e desenvolvimento. In: Dinâmicas de Rede no Turismo Cultural e Religioso - Actas das II Jornadas Internacionais de Turismo, v. II, GONÇALVES, E. C. (Ed.), p. 121-135, $2010 a$.

MARQUES, M. M. A Peregrinação: riqueza ritual. In: Dinâmicas de Rede no Turismo Cultural e Religioso - Actas das II Jornadas Internacionais de Turismo, v. II, GONÇALVES, E. C. (Ed.), p. 243-263, 2010b.

MARQUES, L.; FERREIRA, R. V. O Caminho Português de Santiago: desafios de um itinerário cultural. Revista Turismo e Desenvolvimento, n. 17/18, p. 169-170, 2012.

OFICINA DE ACOGIDA AL PEREGRINO. Disponível em: 〈http://peregrinossantiago.es/esp/oficina-delperegrino/estadisticas/〉. Acesso em: 27 abr. 2015.

OTERO, F. A. Santiago y los Caminos de Santiago: un paisagem cultural, una cultura del paisaje. Boletim de la A.G.E., n. 51, p. 203-218, 2009.

PEDRO, F. Turismo Religioso atrai anualmente sete milhões a Portugal. Jornal de Notícias de 2 de Junho, p. 12, 2014.

PENT. Plano Estratégico Nacional do Turismo de Portugal. Resolução do Conselho de Ministros n. 24/2013. Diário da República, n. 74, I Série, 16/04, p. 2170-2202, 2013. Disponível em: 〈http://www. turismodeportugal.pt/Portugu\%C3\%AAs /turismodeportugal/publicacoes/Documents/PENT\%20 Revisao\%202011.pdf〉.

PINHEIRO, A. E. Itinerários Culturais - Viajando pela História, Máthesis, n. 16, p. 217-228, 2007.

SOLLA, X. M. S. El Camino de Santiago: turistas y peregrinos hacia Compostela, Cadernos de Turismo, n. 18. España: Universidad de Múrcia, p. 135-150, 2006.

XACOBEO GALICIA. Disponível em: 〈http://www.xacobeo.es/〉. Acesso em: 28 mai. 2015. . Los Caminos de Santiago en Galicia - El Camino Português. Folheto informativo, 2013. 